\title{
Clinical outcome of brain metastases differs significantly among breast cancer subtypes
}

\author{
NADJA E. OEHRLICH ${ }^{1}$, LOUKIA M. SPINELI ${ }^{2}$, FRANK PAPENDORF ${ }^{3}$ and TJOUNG-WON PARK-SIMON ${ }^{1}$ \\ Departments of ${ }^{1}$ Gynecology and Obstetrics, and ${ }^{2}$ Biometry; \\ ${ }^{3}$ Clinical Cancer Register Database, Hannover Medical School, D-30625 Hannover, Germany
}

Received July 7, 2016; Accepted November 28, 2016

DOI: $10.3892 / \mathrm{ol} .2017 .6166$

\begin{abstract}
Brain metastases in patients with breast cancer are associated with a poor survival rate. A small number of studies have challenged this premise, suggesting that survival times following brain metastasis differ significantly between breast cancer subtypes. In the current study, overall survival (OS), brain metastases-free survival (BMFS) and survival following brain metastases (SFBM) were found to be associated with the intrinsic breast cancer subtype. A total of 1,147 patients with invasive breast cancer who were treated at the Hannover Medical School between January 2004 and December 2010 were included, from which 54 patients with brain metastases were identified. The Kaplan-Meier method or Cox regression analyses were performed for analysis of survival. OS was found to differ significantly between breast cancer subtypes: OS was significantly shorter in patients with triple-negative (TN) cancer compared with patients with human epidermal growth factor receptor (HER2)-enriched tumors $(\mathrm{P}<0.001)$. In addition, median BMFS times differed significantly between luminal (1,003 days), HER2-enriched (514 days) and $\mathrm{TN}$ breast cancer patients (460 days) $(\mathrm{P}=0.045)$. The median durations of SFBM were 386 days in luminal, 310 days in HER2-enriched and 147 days in TN breast cancer patients $(\mathrm{P}=0.029)$. The results suggested that patients with luminal breast cancer have a lower risk of brain metastases and the most favorable outcome with regard to BMFS, whereas patients with HER2-positive or TN breast cancer have a significantly higher risk of developing brain metastases. Compared with TN breast cancer, the duration of SFBM was doubled in HER2-enriched cancers. These findings may have important implications for treatment and follow-up strategies in patients with breast cancer.
\end{abstract}

Correspondence to: Professor Tjoung-Won Park-Simon, Department of Gynecology and Obstetrics, Hannover Medical School, Carl-Neuberg-Strasse 1, D-30625 Hannover, Germany E-mail: park-simon.tjoung-won@mh-hannover.de

Key words: breast cancer, breast cancer subtypes, brain metastases, survival

\section{Introduction}

Breast cancer is the most frequently occurring cancer type in women and the second most common cause of brain metastases (1). The occurrence of brain metastases is typically associated with a limited survival time as well as reduced quality of life. Brain metastases usually occur late in the disease course of breast cancer, and are uncommon at the time of initial diagnosis of breast cancer $(2,3)$. The risk factors for brain metastases include young age, tumor stage, human epidermal growth factor receptor (HER2)-positivity, triple-negativity, number of metastatic sites $(n>2)$ and large tumor size (4-9). It has been estimated that $10-15 \%$ of patients with breast cancer will develop brain metastases (10), while postmortem studies have detected brain metastases in up to $30 \%$ of patients (11). The median time of brain metastases occurrence is 2-3 years after the initial diagnosis of breast cancer (12). Life expectancy is largely reduced following the diagnosis of brain metastases, with survival time ranging from 2 to 16 months (4). Although screening for brain metastases is not recommended as part of routine clinical care in asymptomatic patients, Miller et al (6) detected brain metastases in $15 \%$ of patients presenting with disseminated breast cancer at the initial screening. Treatment of brain metastases is challenging due to a number of factors; the number and location of brain metastases, performance status of the patient and biological subtype must be taken into consideration (13).

There is growing evidence that the risk of distant metastases differs according to the biological subtype of breast cancer $(3,14)$. Compared with luminal subtypes, HER2-positive (15) and triple-negative (TN) breast cancer tend to spread significantly more often to the brain. However little is known about the subtype-specific outcomes with regard to brain metastases-free survival (BMFS) and survival following brain metastases (SFBM). The present study aimed to determine subtype-specific survival rates among breast cancer patients with brain metastases. The results suggest that in-depth knowledge of the natural history of brain metastases and their clinical outcome may aid in individualizing treatment strategies.

\section{Materials and methods}

Study patients. The present study retrospectively analyzed a cohort of patients with breast cancer who were treated at 
the Hannover Medical School (Hannover, Germany) between January 1st, 2004 and December 31st, 2010. A total of 1,147 patients who met all inclusion criteria were identified from the Hannover Clinical Cancer Register database. The inclusion criteria were primary invasive breast cancer, no previous cancer and no simultaneous cancer of other origin. The exclusion criteria were benign diseases of the breast, ductal carcinoma in situ, microinvasive carcinoma, missing hormone receptor (HR) and/or HER2 receptor status, and rare histology (atypical carcinoid tumor, sclerosing sweat duct carcinoma, signet ring cell carcinoma, sarcoma, myoepithelioma, carcinosarcoma and phyllodes tumor). All patients provided written informed consent and the study was approved by the local ethics committee.

Intrinsic breast cancer subtype. Each primary breast cancer tumor was assessed for HR and HER2 expression by immunohistochemistry (IHC). Immunohistochemical staining was part of routine diagnostics and performed according to the American Society of Clinical Oncology (ASCO)/College of American pathologists (CAP) Clinical Practice Guidelines $(16,17)$. The results of this staining was taken from patients' records. HER2-negativity by clinical assay was defined as IHC $0 / 1+$ or $2+$, confirmed by a fluorescence in situ hybridization (FISH)/chromogenic in situ hybridization amplification ratio of <2.0. Estrogen receptor (ER) and/or progesterone receptor (PR) IHC expression of $\geq 10 \%$ was considered positive. Hormone receptor positivity was defined as ER or PR were positive. Intrinsic subtypes were assigned as follows: Luminal subtype, HR+/HER2-; HER2-enriched subtypes, HR \pm /HER2+; and TN subtype, HR-/HER2-. The results were assigned according to the ASCO/CAP guidelines $(16,17)$.

Outcomes. Overall survival (OS) was defined as the time from the initial breast cancer diagnosis to the final follow-up or mortality. BMFS was defined as the time from breast cancer diagnosis to the diagnosis of brain metastases. SFBM was defined as the time from diagnosis of brain metastases to the date of mortality or last follow-up.

Statistical analysis. Statistical analysis was performed using IBM SPSS Statistics version 22 (IBM SPSS, Armonk, NY, USA) and GraphPad Prism 5 (GraphPad Inc., La Jolla, CA, USA) to create figures. Categorical data were compared with $\chi^{2}$ test or Fisher's exact test, as appropriate. Group differences were calculated using Kruskal-Wallis test for nonparametric data. Survival was estimated by the Kaplan-Meier method and compared with the log-rank (Mantel-Cox) test between breast cancer subtypes. Cox regression analysis was performed to evaluate the hazard ratio and corresponding $95 \%$ confidence interval $(95 \% \mathrm{CI}) . \mathrm{P} \leq 0.05$ was considered to indicate a statistically significant difference. All survival times were calculated in days for the purpose of precise results.

\section{Results}

Patient and tumor characteristics. Patient and tumor characteristics are specified in Table I. Among the 1,147 total patients, 770 patients $(67.13 \%)$ had luminal-type, $202(17.61 \%)$ had HER2-enriched and 175 (15.26\%) had TN breast cancer. Among the group of HER2-enriched tumors, 113 (9.85\%) were HR-positive and 89 (7.76\%) were HR-negative.

Distant metastases were found in 77 of the 1,147 patients $(6.71 \%)$ at the time of diagnosis of breast cancer; in total, 217 patients $(18.92 \%)$ developed distant metastases during the course of the disease. There were 54 patients $(4.71 \%)$ who developed brain metastases, including 9 (11.69\%) who already had brain metastases at the time of initial breast cancer diagnosis. Among those with brain metastases, 12 patients $(1.56 \%)$ had luminal, 20 (9.90\%) had HER2-enriched and 22 (12.57\%) had TN primary breast cancer $(\mathrm{P}<0.001)$. The number and the treatment of brain metastases among these patients are shown in Table II. Between the various intrinsic subtypes of breast cancer, there were no significant differences in the number of brain metastases or the type of treatment, with the exception of antihormone therapy.

Overall survival in the entire study population. The OS time in the entire study cohort $[n=1,147$; median, 1,376 days (46 months)] differed significantly according to breast cancer subtype $(\mathrm{P}<0.001$; Fig. 1A). Patients with TN breast cancer had a significantly shorter OS than patients with luminal breast cancer (hazard ratio, 2.20; 95\% CI, 1.59-3.04; $\mathrm{P}<0.001$ ) and patients with HER2-enriched tumors (hazard ratio, 1.66; 95\% CI, 1.11-2.50; $\mathrm{P}=0.015)$. There was no significant difference between the luminal and HER2-positive breast cancer subtypes (hazard ratio, 1.32; 95\% CI, 0.93-1.89; $\mathrm{P}=0.123$ ). Of the 202 patients with HER2-positive breast cancer, 153 (75.74\%) received anti-HER2 therapy whereas 33 patients $(16.34 \%)$ did not; in the remaining 16 cases $(7.92 \%)$, this information was not available.

It is well-recognized that HER2-positive tumors are of a heterogeneous nature (18). Therefore, a comparison was also performed after dividing the patients into four distinct subgroups: Luminal, HR+/HER2+, HR-/HER2+ and TN subtypes. From this analysis, significant differences in OS were detected $(\mathrm{P}<0.001$; Fig. 1B): Patients with HR-/HER2+ cancer had a significantly reduced OS compared with those with luminal breast cancer $(\mathrm{P}=0.049$; hazard ratio, $1.58 ; 95 \% \mathrm{CI}$, 1.00-2.49); and patients with TN cancer had a significantly poorer OS compared with those with luminal $(\mathrm{P}<0.001$; hazard ratio, 2.20; 95\% $\mathrm{CI}, 1.59-3.04)$ and those with HR+/HER2+ cancer $(\mathrm{P}=0.011$; hazard ratio, 1.97 ; $95 \% \mathrm{CI}, 1.17-3.33)$.

Survival outcomes in patients with brain metastases. Among the 54 patients who developed brain metastases, the median BMFS was 600 days (20 months) (95\% CI, 379.15-820.85 days) and differed significantly by breast cancer subtype. The median BMFS was 1,003 days (33 months) (95\% CI, 840.05-1,165.95 days) in luminal, 514 days (17 months) (95\% CI, 283.91-744.09 days) in HER2-enriched and 460 days (15 months) (95\% CI, 154.33-765.67 days) in TN breast cancer patients $(\mathrm{P}=0.045$; Fig. 2). In addition, slight differences in BMFS were observed when comparing the four distinct breast cancer subtypes $(\mathrm{P}=0.069)$. Patients with HER2-positive breast cancer demonstrated a significantly shorter BMFS compared with patients with the luminal subtype (hazard ratio, 2.62; 95\% CI, 1.19-5.77; $\mathrm{P}=0.017$ ), irrespectively of whether anti-HER2 therapy was received. 
Table I. Baseline characteristics of 1,147 breast cancer patients.

\begin{tabular}{|c|c|c|c|c|c|}
\hline \multirow[b]{2}{*}{ Characteristic } & \multirow[b]{2}{*}{ Luminal } & \multicolumn{2}{|c|}{ HER2-enriched } & \multirow[b]{2}{*}{$\mathrm{TN}$} & \multirow[b]{2}{*}{ P-value } \\
\hline & & HR+/HER2+ & HR-/HER2+ & & \\
\hline Number of patients (\% of total) & $770(67.13)$ & $113(9.85)$ & $89(7.80)$ & $175(15.26)$ & - \\
\hline Age at diagnosis, years & & & & & $<0.001$ \\
\hline Median & 57 & 53 & 50 & 49 & \\
\hline Interquartile range & $47.0-67.0$ & $44.5-64.0$ & $42.0-61.0$ & $38.0-60.0$ & \\
\hline Grade $[\mathrm{n}(\%)]$ & & & & & $<0.001$ \\
\hline G1 & $78(10.13)$ & $1(0.88)$ & $1(1.12)$ & $3(1.71)$ & \\
\hline $\mathrm{G} 2$ & $469(60.91)$ & $48(42.48)$ & $25(28.09)$ & $28(16.00)$ & \\
\hline G3 & $199(25.84)$ & $59(52.21)$ & $58(65.17)$ & $132(75.43)$ & \\
\hline G4 & $0(0.00)$ & $2(1.77)$ & $0(0.00)$ & $5(2.86)$ & \\
\hline GX & $24(3.12)$ & $3(2.65)$ & $5(5.62)$ & $7(4.00)$ & \\
\hline Histology [n (\%)] & & & & & $<0.001$ \\
\hline Invasive ductal carcinoma & $596(77.40)$ & $104(92.04)$ & $81(91.01)$ & $145(82.86)$ & \\
\hline Invasive lobular carcinoma & $118(15.32)$ & $6(5.31)$ & $2(2.25)$ & $3(1.71)$ & \\
\hline Other & $56(7.27)$ & $3(2.65)$ & $6(6.74)$ & $27(15.43)$ & \\
\hline pT stage ${ }^{a}[\mathrm{n}(\%)]$ & & & & & $<0.001$ \\
\hline $\mathrm{pT} 1$ & $397(51.56)$ & $49(43.36)$ & $27(30.34)$ & $63(36.00)$ & \\
\hline pT2 & $208(27.01)$ & $29(25.66)$ & $28(31.46)$ & $52(29.71)$ & \\
\hline pT3 & $34(4.42)$ & $2(1.77)$ & $4(4.49)$ & $5(2.86)$ & \\
\hline pT4 & $13(1.69)$ & $2(1.77)$ & $2(2.25)$ & $3(1.71)$ & \\
\hline Missing/unknown & $118(15.32)$ & $31(27.43)$ & $28(31.46)$ & $52(29.71)$ & \\
\hline $\mathrm{pN}$ stage $^{\mathrm{a}}[\mathrm{n}(\%)]$ & & & & & $<0.001$ \\
\hline pN0 & $402(52.21)$ & $39(34.51)$ & $25(28.09)$ & $72(41.14)$ & \\
\hline $\mathrm{pN} 1$ & $162(21.04)$ & $25(22.12)$ & $13(14.61)$ & $28(16.00)$ & \\
\hline $\mathrm{pN} 2$ & $41(5.32)$ & $8(7.08)$ & $10(11.24)$ & $13(7.43)$ & \\
\hline $\mathrm{pN} 3$ & $38(4.94)$ & $8(7.08)$ & $11(12.36)$ & $7(4.00)$ & \\
\hline Missing/unknown & $127(16.49)$ & $33(29.20)$ & $30(33.71)$ & $55(31.43)$ & \\
\hline ypT stage $^{a}(\mathrm{n}=160)[\mathrm{n}(\%)]$ & & & & & $<0.001$ \\
\hline урT0 & $6(3.75)$ & $3(1.88)$ & $6(3.75)$ & $17(10.63)$ & \\
\hline ypTis & $3(1.88)$ & $2(1.25)$ & $9(5.63)$ & $2(1.25)$ & \\
\hline ypT1 & $28(17.50)$ & $10(6.25)$ & $7(4.38)$ & $12(7.50)$ & \\
\hline урт2 & $19(11.88)$ & $5(3.13)$ & $0(0.00)$ & $9(5.63)$ & \\
\hline ypT3 & $7(4.38)$ & $10.63)$ & $0(0.00)$ & $1(0.63)$ & \\
\hline ypT4 & $4(2.50)$ & $1(0.63)$ & $2(1.25)$ & $3(1.88)$ & \\
\hline Missing/unknown & $1(0.63)$ & $0(0.00)$ & $1(0.63)$ & $1(0.63)$ & \\
\hline ypN stage $^{a}(\mathrm{n}=147)[\mathrm{n}(\%)]$ & & & & & 0.065 \\
\hline ypNO & $26(17.69)$ & $8(5.44)$ & $16(10.88)$ & $31(21.09)$ & \\
\hline ypN1 & $16(10.88)$ & $9(6.12)$ & $6(4.08)$ & $5(3.40)$ & \\
\hline ypN2 & $13(8.84)$ & $3(2.04)$ & $1(0.68)$ & $3(2.04)$ & \\
\hline ypN3 & $3(2.04)$ & $0(0.00)$ & $1(0.68)$ & $1(0.68)$ & \\
\hline Missing/unknown & $3(2.04)$ & $0(0.00)$ & $1(0.68)$ & $1(0.68)$ & \\
\hline Metastases stage $^{\mathrm{a}}[\mathrm{n}(\%)]$ & & & & & 0.032 \\
\hline M0 & $716(92.99)$ & $98(86.73)$ & $77(86.52)$ & $160(91.43)$ & \\
\hline M1 & $46(5.97)$ & $13(11.50)$ & $8(8.99)$ & $10(5.71)$ & \\
\hline MX & $8(1.04)$ & $2(1.77)$ & $4(4.49)$ & $5(2.86)$ & \\
\hline Surgery & & & & & 0.018 \\
\hline No & $29(3.77)$ & $5(4.42)$ & $1(1.12)$ & $3(1.71)$ & \\
\hline Yes & $738(95.84)$ & $105(92.92)$ & $88(98.88)$ & $172(98.29)$ & \\
\hline Unknown & $3(0.39)$ & $3(2.65)$ & $0(0.00)$ & $0(0.00)$ & \\
\hline
\end{tabular}


Table I. Continued.

\begin{tabular}{lccccc}
\hline & & \multicolumn{2}{c}{ HER2-enriched } & & \\
Characteristic & Luminal & HR+/HER2+ & HR-/HER2+ & TN & P-value \\
\hline Chemotherapy (adjuvant/neoadjuvant) [n (\%)] & & & & & $<0.001$ \\
No & $419(54.42)$ & $21(18.58)$ & $9(10.11)$ & $25(14.29)$ & \\
Yes & $296(38.44)$ & $82(72.57)$ & $72(80.90)$ & $134(76.57)$ & \\
Missing/unknown & $55(7.14)$ & $10(8.85)$ & $8(8.99)$ & $16(9.14)$ & \\
Antihormone therapy [n (\%)] & & & & & $<0.001$ \\
No & $49(6.36)$ & $11(9.73)$ & $82(92.13)$ & $167(95.43)$ & \\
Yes & $535(69.48)$ & $80(70.80)$ & $6(6.74)$ & $6(3.43)$ & \\
Unknown & $186(24.16)$ & $22(19.47)$ & $1(1.12)$ & $2(1.14)$ & \\
Anti-HER2 therapy [n (\%)] & & & & & $<0.001$ \\
No & $752(97.66)$ & $20(17.70)$ & $13(14.61)$ & $172(98.29)$ & \\
Yes & $3(0.39)$ & $83(73.45)$ & $70(78.65)$ & $1(0.57)$ & \\
Unknown & $15(1.95)$ & $10(8.85)$ & $6(6.74)$ & $2(1.14)$ & \\
Distant metastases (overall) [n (\%)] & & & & & $<0.001$ \\
No & $652(84.68)$ & $91(80.53)$ & $62(69.66)$ & $125(71.43)$ & \\
Yes & $118(15.32)$ & $22(19.47)$ & $27(30.34)$ & $50(28.57)$ & \\
Brain metastases at breast cancer diagnosis [n(\%)] & & & & & 0.020 \\
No & $768(99.74)$ & $110(97.35)$ & $88(98.88)$ & $172(98.29)$ & \\
Yes & $2(0.26)$ & $3(2.65)$ & $1(1.2)$ & $3(1.71)$ & $<0.001$ \\
Brain metastases (overall) [n (\%)] & & & & \\
No & $758(98.44)$ & $106(93.81)$ & $76(85.39)$ & $153(87.43)$ & \\
Yes & $12(1.56)$ & $7(6.19)$ & $13(14.61)$ & $22(12.57)$ & \\
\hline
\end{tabular}

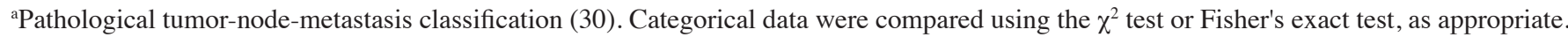
HER2, human epidermal growth factor receptor 2; HR, hormone receptor; TN, triple-negative; T stage, tumor stage; N stage, node stage.
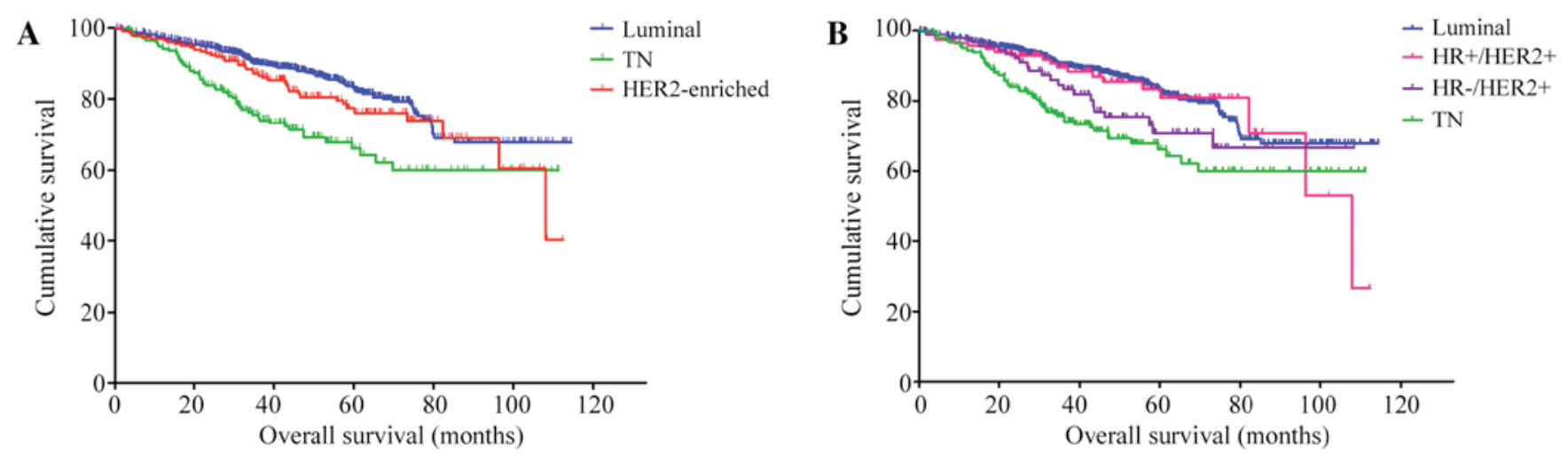

Figure 1. Overall survival of breast cancer patients $(n=1,147)$ by subtype. (A) Cumulative survival of breast cancer patients according to luminal, TN and HER2-enriched subtypes was estimated by the Kaplan-Meier method. (B) Cumulative survival of breast cancer patients according to luminal, TN, HR+/HER2+ and HR-/HER2+ subtypes was estimated by the Kaplan-Meier method. TN, triple-negative; HER2, human epidermal growth factor receptor 2; HR, hormone receptor.

The median duration of SFBM was 246 days (8 months) (95\% CI, 128.65-363.35 days) and this differed significantly among the subtypes ( $\mathrm{P}=0.029$; Fig. $3 \mathrm{~A})$ : The median duration of SFBM was 386 days (13 months) (95\% CI, 0.00-914.26 days) in luminal, 310 days (10 months) (95\% CI, 0.00-658.19 days) in HER2-enriched and 147 days (5 months) (95\% CI, 109.64-184.36 days) in TN breast cancer patients.
With regard to luminal, HR+/HER2+, HR-/HER2+ and TN breast cancer subtypes, the median durations of SFBM were 386 days (13 months) (95\% CI, 0.00-914.26 days), 837 days (28 months) (95\% CI, 0.00-2,301.57 days), 310 days (10 months) (95\% CI, 227.49-392.51 days) and 147 days (5 months) (95\% CI, 109.64-184.36 days), respectively $(\mathrm{P}=0.042$; Fig. 3B). Patients with TN cancer had a significantly 
Table II. Number of brain metastases and treatment within the subgroup of 54 breast cancer patients who developed brain metastases.

\section{HER2-enriched}

\begin{tabular}{|c|c|c|c|c|c|}
\hline & & & & & \\
\hline Characteristic & Luminal & HR+/HER2+ & HR-/HER2+ & $\mathrm{TN}$ & P-value \\
\hline Number of patients ( $\%$ of total) & $12(22.22)$ & $7(12.96)$ & $13(24.07)$ & $22(40.74)$ & - \\
\hline Number of brain metastases $[\mathrm{n}(\%)]$ & & & & & 0.395 \\
\hline 1 & $1(8.33)$ & $3(42.86)$ & $3(23.08)$ & $4(18.18)$ & \\
\hline$\geq 2$ & $5(41.67)$ & $3(42.86)$ & $8(61.54)$ & $17(77.27)$ & \\
\hline Missing/unknown & $3(25.00)$ & $1(14.29)$ & $2(15.38)$ & $1(4.55)$ & \\
\hline Treatment of brain metastases $[\mathrm{n}(\%)]$ & & & & & 0.664 \\
\hline Surgery & & & & & \\
\hline No & $7(58.33)$ & $2(28.57)$ & $6(46.15)$ & $12(54.55)$ & \\
\hline Yes & $5(41.67)$ & $5(71.43)$ & $6(46.15)$ & $8(36.36)$ & \\
\hline Unknown & $0(0.00)$ & $0(0.00)$ & $1(7.69)$ & $2(9.09)$ & \\
\hline Radiotherapy & & & & & 0.350 \\
\hline No & $5(41.67)$ & $2(28.57)$ & $2(15.38)$ & $2(9.09)$ & \\
\hline Yes & $7(58.33)$ & $5(71.43)$ & $10(76.92)$ & $18(81.82)$ & \\
\hline Unknown & $0(0.00)$ & $0(0.00)$ & $1(7.69)$ & $2(9.09)$ & \\
\hline Chemotherapy & & & & & 0.346 \\
\hline No & $11(91.67)$ & $457.14)$ & $7(53.85)$ & 13 (59.09) & \\
\hline Yes & $1(8.33)$ & $3(42.86)$ & $4(30.77)$ & $7(31.82)$ & \\
\hline Unknown & $0(0.00)$ & $0(0.00)$ & $2(15.38)$ & $2(9.09)$ & \\
\hline Antihormone therapy & & & & & 0.021 \\
\hline No & $9(75.00)$ & $4(57.14)$ & $12(92.31)$ & $20(90.91)$ & \\
\hline Yes & $3(25.00)$ & $3(42.86)$ & $0(0.00)$ & $0(0.00)$ & \\
\hline Unknown & $0(0.00)$ & $0(0.00)$ & $1(7.69)$ & $2(9.09)$ & \\
\hline Immunotherapy & & & & & 0.217 \\
\hline No & $12(100.0)$ & $5(71.43)$ & $9(69.23)$ & $19(86.36)$ & \\
\hline Yes & $0(0.00)$ & $2(28.57)$ & $3(23.08)$ & $1(4.55)$ & \\
\hline Unknown & $0(0.00)$ & $0(0.00)$ & $1(7.69)$ & $2(9.09)$ & \\
\hline
\end{tabular}

Categorical data were compared with $\chi^{2}$ test or Fisher's exact test as appropriate. HER2, human epidermal growth factor receptor 2; HR, hormone receptor; $\mathrm{TN}$, triple-negative.

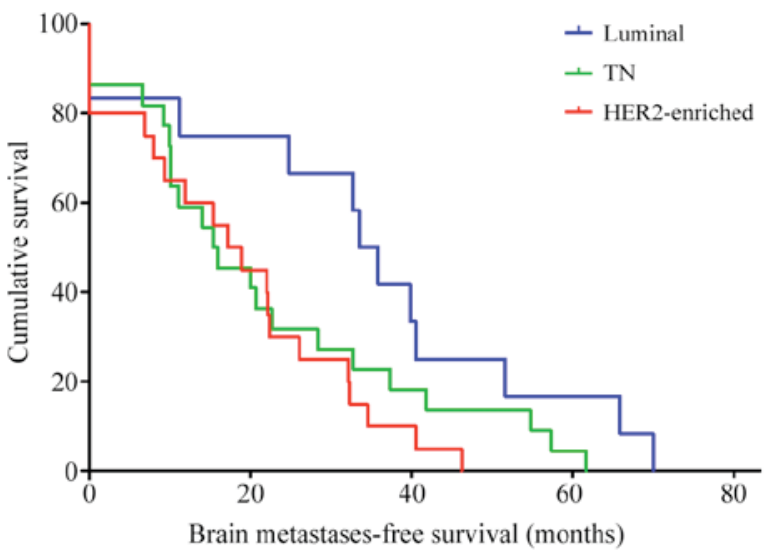

Figure 2. Brain metastases-free survival of breast cancer patients by subtype estimated by Kaplan-Meier method ( $\mathrm{n}=54)$ : Luminal [median, 1,003 days (33 months); 95\% CI, 840.05-1,165.95 days], HER2-enriched [median, 514 days (17 months); 95\% CI, 283.91-744.09 days], TN [median, 460 days (15 months); 95\% CI, 154.33-765.67 days]. CI, confidence interval; HER2, human epidermal growth factor receptor 2 ; TN, triple-negative. shorter SFBM compared with that of HER2-positive patients $(\mathrm{P}=0.013$; hazard ratio, 2.66; 95\% CI, 1.23-5.73), particularly those with the HR+/HER2+ subtype $(\mathrm{P}=0.013$; hazard ratio, 4.44; 95\% CI, 1.36-14.49).

$\mathrm{OS}$ in the 54 patients with brain metastases did not differ significantly between breast cancer subtypes $(\mathrm{P}=0.180)$. The median OS times were 1,282 days (43 months) (95\% CI, 817.03-1,746.97 days) in patients with HER2-enriched breast cancer, 664 days (22 months) (95\% CI, 338.79-989.21 days) in patients with TN breast cancer and 1,690 days (56 months) (95\% CI, 1,038.21-2,341.79 days) in patients with luminal breast cancer.

\section{Discussion}

The incidence of brain metastasis detection in breast cancer is increasing due to advances in imaging technologies and the introduction of novel therapies resulting in longer survival 

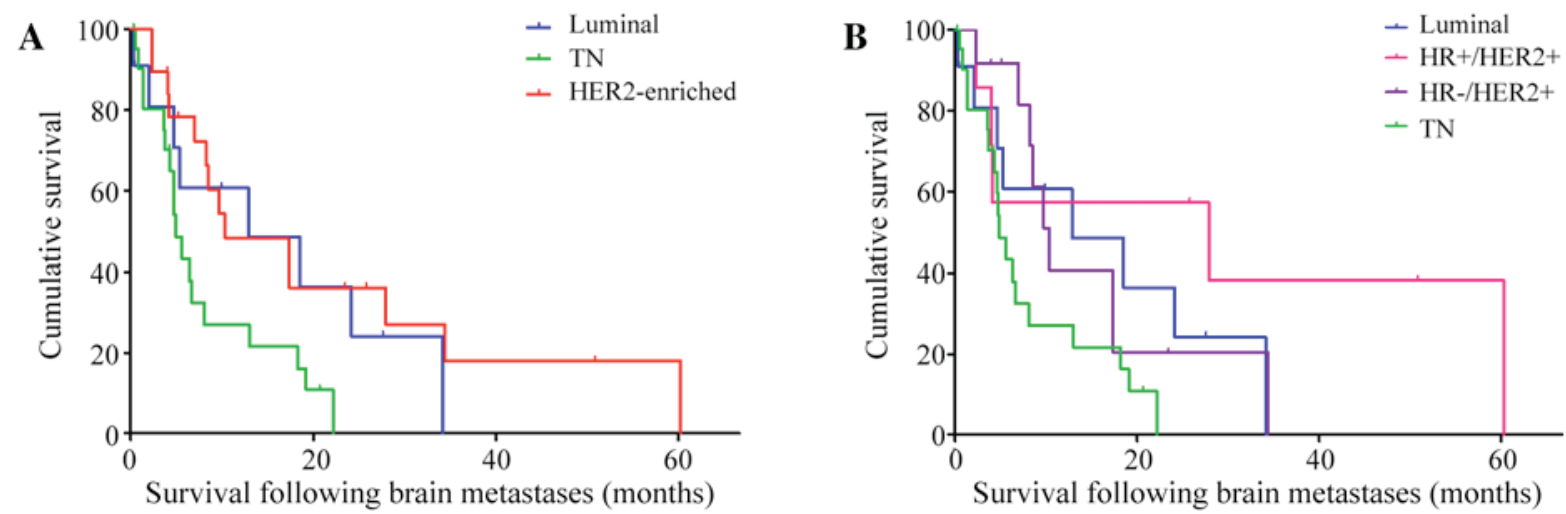

Figure 3. Survival following brain metastases of breast cancer patients ( $\mathrm{n}=54)$ by subtype, estimated by Kaplan-Meier method. (A) Survival according to luminal (median, 13 months; 95\% CI, 0.00-914.26 days), HER2-enriched (median, 10 months; 95\% CI, 0.00-658.19 days) and TN (median, 5 months; 95\% CI, 109.64-184.36 days) subtypes. (B) Survival according to luminal (median, 13 months; 95\% CI, 0.00-914.26 days), HR+/HER2+ (median, 28 months; $95 \%$ CI, 0.00-2,301.57 days), HR-/HER2+ (median, 10 months; 95\% CI, 227.49-392.51 days), TN (median, 5 months; 95\% CI, 109.64-184.36 days). CI, confidence interval; HER2, human epidermal growth factor receptor 2; TN, triple-negative; HR, hormone receptor.

times $(9,19)$. In-depth understanding of the natural history of brain metastases can aid in the optimization of treatment and follow-up strategies.

It is accepted that the risk of metastasis and the survival times vary significantly among breast cancer subtypes, which was confirmed in the current single-institution cohort study. Patients with TN breast cancer had a significantly decreased OS compared with those with luminal or HER2-positive breast cancer subtypes. However, no significant difference in OS was identified between luminal and HER2-positive breast cancer, which is most likely attributable to the fact that the majority of HER2-positive patients that were included in this study received HER2-targeted treatment.

Due to the limited number of patients in the current study, OS did not significantly differ among patients with brain metastases with different intrinsic subtypes. However numerically, OS was longest in patients with luminal breast cancer [1,690 days (56 months)] compared with patients with HER2-enriched [1,282 days (43 months)] and TN cancers [664 days (22 months)]. These differences may be explained, in part, by the differences in BMFS; metastases of luminal breast cancer occur rather late in the course of the disease $(4,20)$. In fact, it was demonstrated that BMFS varies significantly between breast cancer subtypes, with luminal breast cancer patients showing the most favorable outcome. The median BMFS was 33 months in luminal compared to 17 months in HER2-enriched and 15 months in TN breast cancer patients $(\mathrm{P}=0.045)$.

SFBM significantly differed in the current study cohort $(\mathrm{P}=0.042)$. TN patients had the poorest survival time (5 months) compared with luminal (13 months), HR+/HER2+ (28 months) and HR-/HER2+ (10 months) tumors, respectively. These findings are consistent with previous reports demonstrating that the median length of SFBM is $<6$ months in patients with TN breast cancers (21-23). This indicates that treatment strategies for TN patients with brain metastases should be carefully selected and should acknowledge the limited prognosis. By contrast, SFBM was doubled in HER2-enriched cancer cases (10 months) compared with TN breast cancers (5 months), despite similar BMFS times; this may reflect the high efficiency of HER2-targeted treatment strategies $(21,24)$.
With regard to brain metastases in cases of the luminal subtype, data varies among studies; certain authors have reported a median SFBM similar to that of TN patients (22), speculating that the lack of further treatment options later in the course of the disease could explain the poor prognosis. By contrast, the present data and that of Niwińska et al (23) demonstrated median SFBMs in luminal tumors of 13 months and 15 months, respectively. In the present study, the survival time of this subgroup was longer than that of patients with TN or HR-/HER2+ breast cancer.

In the past, HER2-positive breast cancer has been considered as a single disease entity. However, there is mounting evidence to suggest that HER2-positive breast cancers are clinically and biologically heterogeneous (18). This is recognized by the St. Gallen's criteria, which divide HER2-positive disease into two groups: ER+/HER2+ and ER-/HER2+ (25). In the present study, $\sim 75 \%$ of the patients with HER2-positive breast cancer received HER2-targeted treatment. The OS in HR-/HER2+ patients was significantly shorter compared with that of patients with luminal breast cancer $(\mathrm{P}=0.049$; hazard ratio, $1.58 ; 95 \% \mathrm{CI}, 1.00-2.49)$. By contrast, the OS of $\mathrm{HR}+$ /HER2+ patients was comparable to that of luminal breast cancer. These findings are in line with previous studies, which have shown that adjuvant treatment with trastuzumab is associated with a $40 \%$ increase in disease-free survival and $\mathrm{OS}$ times in HR+/HER2+ cancers as compared with HR-/HER2+ cancers $(26,27)$.

There are several limitations of the present study. All patients included in this retrospective analysis were treated at a single institution between 2004-2010, and only 54 patients with brain metastases met all inclusion and exclusion criteria of the study. Therefore, subgroup analysis must be interpreted with caution. Due to the small and varying subgroup sizes of the patients with brain metastases, a distinct multivariate analysis was not appropriate. In addition, immunohistochemical staining and FISH analysis were used to define subtypes of breast cancer, rather than gene expression analysis. However, considerable efforts have been made to ensure the high-quality of immunohistochemical analysis of steroid hormone receptors and HER2 status (28). Despite these efforts, immunostaining remains only a surrogate marker of 
intrinsic molecular breast cancer subtypes. Furthermore, since brain metastases tissue was not available for all cases, biological discordance between the primary breast cancer and the brain metastases cannot be excluded.

In conclusion, the prognosis of breast cancer subtypes varies significantly in patients with brain metastases. This could have important implications for treatment and follow-up strategies. Patients with luminal breast cancer have a low risk of developing brain metastases per se, and symptom-based clinical follow-up seems appropriate. Patients with HER2-positive or TN breast cancer have a significantly higher risk of developing brain metastases. Compared to $\mathrm{TN}$ breast cancer, the survival times of metastatic HER2-positive breast cancer have improved significantly over the past years due to the availability of novel powerful HER2-directed drugs $(19,29)$. Therefore this subgroup of patients may benefit from closer clinical and imaging follow-up examinations.

\section{References}

1. Lassman AB and DeAngelis LM: Brain metastases. Neurol Clin 21: 1-23, vii, 2003.

2. Stark AM: Neurosurgical treatment of breast cancer metastases to the neurocranium. Patholog Res Int 2011: 549847, 2010.

3. Sihto H, Lundin J, Lundin M, Lehtimäki T, Ristimäki A, Holli K, Sailas L, Kataja V, Turpeenniemi-Hujanen T, Isola J, et al: Breast cancer biological subtypes and protein expression predict for the preferential distant metastasis sites: A nationwide cohort study. Breast Cancer Res 13: R87, 2011.

4. Weil RJ, Palmieri DC, Bronder JL, Stark AM and Steeg PS: Breast cancer metastasis to the central nervous system. Am J Pathol 167: 913-920, 2005.

5. Heitz F, Rochon J, Harter P, Lueck HJ, Fisseler-Eckhoff A, Barinoff J, Traut A, Lorenz-Salehi F and du Bois A: Cerebral metastases in metastatic breast cancer: Disease-specific risk factors and survival. Ann Oncol 22: 1571-1581, 2011.

6. Miller KD, Weathers T, Haney LG, Timmerman R, Dickler M, Shen J and Sledge GW Jr: Occult central nervous system involvement in patients with metastatic breast cancer: Prevalence, predictive factors and impact on overall survival. Ann Oncol 14: 1072-1077, 2003.

7. Heitz F, Harter P, Lueck HJ, Fissler-Eckhoff A, Lorenz-Salehi F, Scheil-Bertram S, Traut A and du Bois A: Triple-negative and HER2-overexpressing breast cancers exhibit an elevated risk and an earlier occurrence of cerebral metastases. Eur J Cancer 45: 2792-2798, 2009.

8. Pestalozzi BC, Zahrieh D, Price KN, Holmberg SB, Lindtner J, Collins J, Crivellari D, Fey MF, Murray E, Pagani O, et al: Identifying breast cancer patients at risk for central nervous system (CNS) metastases in trials of the international breast cancer study group (IBCSG). Ann Oncol 17: 935-944, 2006.

9. Niikura N, Saji S, Tokuda Y and Iwata H: Brain metastases in breast cancer. Jpn J Clin Oncol 44: 1133-1140, 2014.

10. DiStefano A, Yong Yap Y, Hortobagyi GN and Blumenschein GR: The natural history of breast cancer patients with brain metastases. Cancer 44: 1913-1918, 1979.

11. Tsukada Y, Fouad A, Pickren JW and Lane WW: Central nervous system metastasis from breast carcinoma. Autopsy study. Cancer 52: 2349-2354, 1983.

12. Cheng $X$ and Hung MC: Breast cancer brain metastases. Cancer Metastasis Rec 26: 635-643, 2007.

13. Leone JP and Leone BA: Breast cancer brain metastases: The last frontier. Exp Hematol Oncol 4: 33, 2015.

14. Kennecke H, Yerushalmi R, Woods R, Cheang MC, Voduc D, Speers CH, Nielsen TO and Gelmon K: Metastatic behavior of breast cancer subtypes. J Clin Oncol 28: 3271-3277, 2010

15. Palmieri D, BronderJL, Herring JM, Yoneda T, Weil RJ,Stark AM, Kurek R, Vega-Valle E, Feigenbaum L, Halverson D, et al: Her-2 overexpression increases the metastatic outgrowth of breast cancer cells in the brain. Cancer Res 67: 4190-4198, 2007.
16. Wolff AC, Hammond ME, Hicks DG, Dowsett M, McShane LM, Allison KH, Allred DC, Bartlett JM, Bilous M, Fitzgibbons $\mathrm{P}$, et al: Recommendations for human epidermal growth factor receptor 2 testing in breast cancer: American society of clinical oncology/college of American pathologists clinical practice guideline update. J Clin Oncol 31: 3997-4013, 2013.

17. Hammond ME, Hayes DF, Dowsett M, Allred DC, Hagerty KL, Badve S, Fitzgibbons PL, Francis G, Goldstein NS, Hayes M, et al: American society of clinical oncology/college of American pathologists guideline recommendations for immunohistochemical testing of estrogen and progesterone receptors in breast cancer. J Clin Oncol 28: 2784-2795, 2010.

18. Blows FM, Driver KE, Schmidt MK, Broeks A, van Leeuwen FE, Wesseling J, Cheang MC, Gelmon K, Nielsen TO, Blomqvist C, et al: Subtyping of breast cancer by immunohistochemistry to investigate a relationship between subtype and short and long term survival: A collaborative analysis of data for 10,159 cases from 12 studies. PLoS Med 7: e1000279, 2010.

19. Rostami R, Mittal S, Rostami P, Tavassoli F and Jabbari B: Brain metastasis in breast cancer: A comprehensive literature review. J Neurooncol 127: 407-414, 2016.

20. Berghoff A, Bago-Horvath Z, De Vries C, Dubsky P, Pluschnig U, Rudas M, Rottenfusser A, Knauer M, Eiter H, Fitzal F, et al: Brain metastases free survival differs between breast cancer subtypes. Br J Cancer 106: 440-446, 2012.

21. Anders CK, Deal AM, Miller CR, Khorram C, Meng H, Burrows E, Livasy C, Fritchie K, Ewend MG, Perou CM and Carey LA: The prognostic contribution of clinical breast cancer subtype, age and race among patients with breast cancer brain metastases. Cancer 117: 1602-1611, 2011.

22. Nam BH, Kim SY, Han HS, Kwon Y, Lee KS, Kim TH and Ro J: Breast cancer subtypes and survival in patients with brain metastases. Breast Cancer Res 10: R20, 2008.

23. Niwińska A, Murawska M and Pogoda K: Breast cancer brain metastases: Differences in survival depending on biological subtype, RPA RTOG prognostic class and systemic treatment after whole-brain radiotherapy (WBRT). Ann Oncol 21: 942-948, 2010.

24. Park YH, Park MJ, Ji SH, Yi SY, Lim DH, Nam DH, Lee JI, Park W, Choi DH and Huh SJ: Trastuzumab treatment improves brain metastasis outcomes through control and durable prolongation of systemic extracranial disease in HER2-overexpressing breast cancer patients. Br J Cancer 100: 894-900, 2009.

25. Goldhirsch A, Wood WC, Coates AS, Gelber RD, Thürlimann B and Senn HJ; Panel members: Strategies for subtypes-dealing with the diversity of breast cancer: Highlights of the St Gallen international expert consensus on the primary therapy of early breast cancer 2011. Ann Oncol 22: 1736-1747, 2011.

26. Perez EA, Romond EH, Suman VJ, Jeong JH, Davidson NE, Geyer CE Jr, Martino S, Mamounas EP, Kaufman PA and Wolmark N: Four-year follow-up of trastuzumab plus adjuvant chemotherapy for operable human epidermal growth factor receptor 2-positive breast cancer: Joint analysis of data from NCCTG N9831 and NSABP B-31. J Clin Oncol 29: 3366-3373, 2011.

27. Vaz-Luis I, Ottesen RA, Hughes ME, Marcom PK, Moy B, Rugo HS, Theriault RL, Wilson J, Niland JC, Weeks JC and Lin NU: Impact of hormone receptor status on patterns of recurrence and clinical outcomes among patients with human epidermal growth factor-2-positive breast cancer in the national comprehensive cancer network: A prospective cohort study. Breast Cancer Res 14: R129, 2012.

28. Wasielewski Rv, Hasselmann S, Rüschoff J, Fisseler-Eckhoff A and Kreipe H: Proficiency testing of immunohistochemical biomarker assays in breast cancer. Virchows Arch 453: 537-543, 2008.

29. Yao H, He G, Yan S, Chen C, Song L, Rosol TJ and Deng X: Triple-negative breast cancer: Is there a treatment on the horizon? Oncotarget: Sep 27, 2016 (Epub ahead of print). doi: 10.18632/oncotarget.12284.

30. Sobin LH, Gospodarowicz MK and Wittekind C: TNM classification of malignant tumours, UICC, International Union against Cancer, 7th edition, Wiley-Blackwell, 2010. 